International Journal of Engineering \& Technology, $7(2.23)(2018) 238-241$
International Journal of Engineering \& Technology
SPC
Website www.sciencepubco.com/index.php/IJET
Research paper

\title{
Calculation of plate-beam systems by method of boundary elements
}

\author{
Mykola Surianinov ${ }^{1 *}$, Oleksii Shyliaiev² \\ ${ }^{1}$ Professor, Department of structural mechanics, Odesa State Academy of Civil Engineering and Architecture, Odesa, Ukraine \\ ${ }^{2}$ Assistant lecture, Department of structural mechanics, Odesa State Academy of Civil Engineering and Architecture, Odesa, Ukraine \\ *E-mail: sng@ogasa.org.ua
}

\begin{abstract}
The approach to calculation of plate-beam systems by numerical and analytical method of boundary elements is proposed. The method consists in construction in analytical way a fundamental system of solutions, the Green's function and external load vector for the problem under consideration. Small system of linear algebraic equations to be solved numerically is constructed to take into account the boundary conditions or contact conditions between separate modules.

The series of plate-beam system calculations by methods of boundary elements and finite elements at different geometric parameters of plate was performed to assess the limits of applicability of developed theory. The comparison of 45 variants calculations by both methods is shown.
\end{abstract}

Keywords: Plate, Supporting Beam, Finite Element, Boundary Element, ANSYS.

\section{Introduction}

Calculation of monolithic ribbed overlapping in traditional design is reduced to separate calculations of main and secondary beams and monolithic plate as beam structures without taking into account the effect of their interaction on stress-strain state.

The overall disadvantage of monolithic overlapping calculation methods at their traditional design is a lack of spatial work consideration and as a result underestimation or overestimations of their strength and crack resistance.

Meanwhile, reinforced concrete plate-beam systems are widely used in construction, in particular in bridge construction they are used in more than $90 \%$ of operated or spans or spans under construction.

\section{Problem formulation}

Plate-beam system is a connection of two different types of elements, which interacts at deformation - plates and ribs (onedimensional rod). The stress-strain state of each of these elements, conditioned in the framework of known applied theories, has its own peculiarities. Concerning this at studying of such systems there is a need in a special theory construction, which consider main features inherent in separate elements and conditions of their common work. Analytical solutions of problem are not currently achieved. Calculations by numerical methods (mainly by the finite element method) require appropriate verification, so the development of new approaches seems very relevant.

\subsection{Aim of paper}

The aim of this work is an application of numerical and analytical method of boundary elements to calculation of rectangular plate, supported by webbing in two directions with following verification of obtained results. For considering of certain

\subsection{Materials and methods}

Numerical and analytical method of boundary elements [1-3] is a developed by authors variant of classic method of boundary elements (BEM) [4-6]. Method consists in construction of fundamental system of equations (analytically) and Green's functions (analytically too) for each of considered problems. For considering of certain boundary conditions or contact conditions between separate modules (as we call the separate element of system) a small system of linear algebraic equations is constructed. It should be solved numerically.

Implementation of algorithms of numerical and analytical BEM is mainly carried out by programs written in the language of MATLAB [7] environment and each program is of a local nature, that it is designed to solve a particular problem - calculation of beam, arc, frame, etc. The same programs can be implemented in Scilab [8] or in the Delphi environment [9]. BEM matrix construction for the use of these programs is performed "manually" and proves to be quite labour-intensive. Therefore, a universal program is developed on more powerful and platform-independent programming language Java [10]. 


\section{Research results}

Differential equation of bending of plate-beam system, which is considered as a plate, supported by webbing has a form [1]:

$\frac{\partial^{4} W}{\partial x^{4}}+2 \frac{\partial^{4} W}{\partial x^{2} \partial y^{2}}+\frac{\partial^{4} W}{\partial y^{4}}=\frac{\bar{q}}{D}$

where $W=W(x, y)$ - plate deflection; $\bar{q}=\bar{q}(x, y)$ - free term of equation which takes into account not just external loads, but presence of supporting webbing in longitudinal direction, by which we mean the direction, parallel to axis $y$ (Figure 1).

$$
\begin{aligned}
& \bar{q}(x, y)=q(x, y)-\sum_{i=1}^{n} E I_{x} W^{I V}(y) X\left(a_{i}\right) \delta\left(x-a_{i}\right)- \\
& -\sum_{i=1}^{n} \frac{G A}{k_{1}} W^{\prime \prime}(y) X\left(a_{i}\right) \delta\left(x-a_{i}\right)- \\
& \sum_{i=1}^{n}\left[E I_{\omega} W^{I V}(y) X^{\prime}\left(a_{i}\right)-G I_{K} W^{\prime \prime}(y) X^{\prime}\left(a_{i}\right)\right] \delta\left(x-a_{i}\right),
\end{aligned}
$$

where $E I_{x}, E I_{\omega}, E I_{k}$ - ribs stiffness at bending and torsion, $k_{1}-$ coefficient, which takes into account the form of the shape; $a_{i}$ coordinate of $i$-th rib location (Figure 1).

For rectangular section $k_{1}=1.2$. In general case the coefficient $k_{1}$ is defined by expression:

$$
k_{1}=\frac{A_{v}(z)}{B_{x}^{2}(z)} \int_{A} \frac{S_{E y A}^{2}}{G b^{2}} d A,
$$

where $A-$ the section area; $A_{v}=\int_{A} G d A ; B_{x}(z)=\int_{A} E y^{2} d A$; $S_{E y A}=\int_{A} E x d A$.

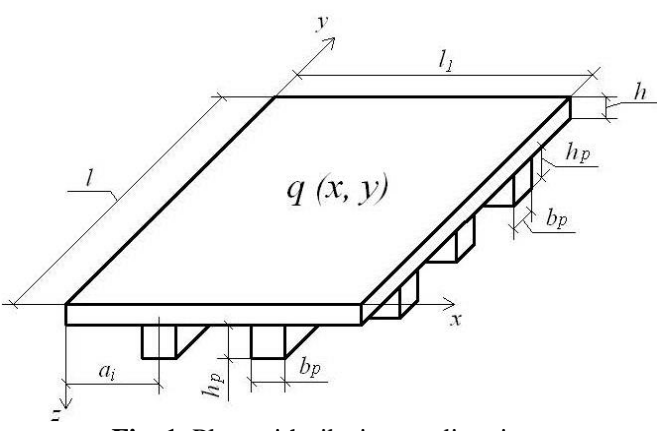

Fig. 1. Plate with ribs in two directions

This problem is two-dimensioned. In numerical and analytical method of boundary elements plates and shells are considered as a generalized one-dimensioned modules. Therefore, it is needed to apply variational method of Kantorovich-Vlasov and as a result we will obtain differential equation with constant coefficients:

$$
W^{I V}(y)-2 r^{2} W^{\prime \prime}(y)+s^{4} W(y)=\frac{\bar{q}(y)}{D}
$$

After construction of fundamental functions, Green's function and external load vectors formation (appropriate procedures are described in [1]) the algorithm of numerical and analytical method of boundary elements [1] for any kind of boundary conditions and arbitrary number of beams (of continuous and thin-walled crosssection) in both directions can be implemented.

The general concept of proposed approach is as follows. Plate's parts that are supported by beams in transverse direction (parallel to the $O x$ axle) are considered as "smooth" plates with thickness of $h_{1}=h+h_{p}$, where $h$ - thickness of plate, $h_{p}$ - height of supporting beam. The theory of "smooth" plates calculation by the method of boundary elements with corresponding expressions of fundamental functions, Green's function, load vectors, etc. is applicable for these modules. Other modules represent plates supported with beams in longitudinal direction (parallel to the $O y$ axle) and for them fundamental functions, Green's functions, load vectors are defined by expressions, which are obtained for ribbed plates.

At numerical and analytical method of boundary elements use the natural question of applicability limits of proposed theory arise. How do the beam parameters and their number affect the accuracy of the solution? What is the role of the relationship between the geometric dimensions of the plate and beams? Is our theory true if the beams have a thin-walled section, not a solid one? To answer all these questions, it is necessary to carry out computer experiments, changing the dimensions of the plate and beams, the number of beams, the nature of the external load and boundary conditions. It is needed to do this in two ways and then compare the results. One of these methods will be the proposed approach based on BEM, and as the second method the finite element method implemented in the ANSYS program is chosen.

We will present here only a part of considered variants, namely, 45 variants of calculation at different parameters of beams and plate. Wherein parameters being changed took following values:

- number of beams in longitudinal direction - 1, 3, 5;

- number of beams in transverse direction - 1, 3, 5;

- plate length ( $l$, Figure 1$)-1 \mathrm{~m}, 2 \mathrm{~m}, 3 \mathrm{~m}$;

- plate thickness ( $h$, Figure 1$)-0.0125 \mathrm{~m}, 0.05 \mathrm{~m}, 0.1 \mathrm{~m}$, $0.335 \mathrm{~m}$.

In all calculations the plate is fixed by contour and loaded by uniformly distributed on all surface load $q=10 \mathrm{kN} / \mathrm{m}$. Width of plate $\left(l_{1}=1 \mathrm{~m}\right.$, Figure 1$)$ and beams cross-section dimensions ( $h_{p}=b_{p}=0,1 m$, Figure 1) remained unchanged.

Both of applied methods of calculation (BEM and FEM) allows to determine a whole range of parameters of stress-strain state of plate-beam system - internal forces, deflections, stresses, deformations. The following tables shows only some of them - deflection in the centre of the plate, maximum deflection, stress in the centre of the plate and maximum stress.

Calculations results of stated values at one rib in both directions are shown in Table 1, at three ribs - in Table 2 and at five ribs - in Table 3.

By the data of these tables there was plotted the graphics of relation between deflection in the centre of the plate and its thickness at one (Figure 2), and five (Figure 3) beams and graphics of relation between maximum stresses in plate and its thickness at three (Figure 4) and five (Figure 5) beams in both directions.

Results of analogical calculations by finite element method in the ANSYS software are not given here due to limited amount of the paper. We note only that the discrepancy in the results increases with the ratio of the height of the transverse supporting beam to the thickness of the plate and is practically independent of the ratio of the height of the longitudinal supporting beam to the thickness of the plate.

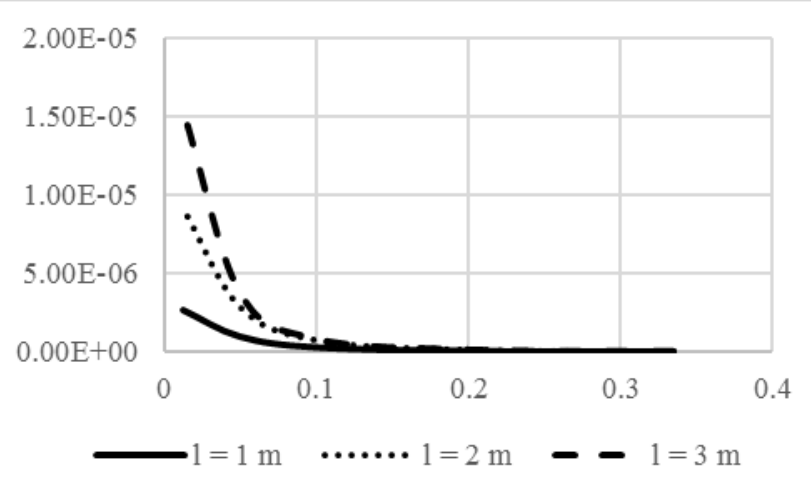

Fig. 2. Graphics of relation between deflection in the centre of the plate (vertical axis, $\mathrm{m}$ ) to its thickness (horizontal axis, $\mathrm{m}$ ) at one rib 
Table 1: Calculations results at one rib in every direction

\begin{tabular}{|c|c|c|c|c|c|c|}
\hline № & $\begin{array}{c}\text { Plate length, } \\
\mathrm{m}\end{array}$ & $\begin{array}{l}\text { Plate thickness, } \\
\text { m }\end{array}$ & $\begin{array}{l}\text { Deflection in the cen- } \\
\text { tre of plate, } m\end{array}$ & $\begin{array}{l}\text { Maximum deflec- } \\
\text { tion, } \mathrm{m}\end{array}$ & $\begin{array}{c}\text { Stress in the centre of } \\
\text { plate, } \mathrm{Pa}\end{array}$ & Maximum stress, $\mathrm{Pa}$ \\
\hline 1 & 1 & 0.335 & $0.14974 \cdot 10^{-7}$ & $0.14974 \cdot 10^{-7}$ & 8905.1 & 19789.0 \\
\hline 2 & 1 & 0.2 & $0.58752 \cdot 10^{-7}$ & $0.58752 \cdot 10^{-7}$ & 18550.0 & 50862.0 \\
\hline 3 & 1 & 0.1 & $0.29159 \cdot 10^{-6}$ & $0.29159 \cdot 10^{-6}$ & 31875.0 & $0.17118 \cdot 10^{6}$ \\
\hline 4 & 1 & 0.05 & $0.96359 \cdot 10^{-6}$ & $0.96359 \cdot 10^{-6}$ & 20710.0 & $0.37324 \cdot 10^{6}$ \\
\hline 5 & 1 & 0.0125 & $0.26320 \cdot 10^{-5}$ & $0.23284 \cdot 10^{-4}$ & 95109.0 & $0.41674 \cdot 10^{7}$ \\
\hline 6 & 2 & 0.335 & $0.31924 \cdot 10^{-7}$ & $0.31928 \cdot 10^{-7}$ & 14863.0 & 33300.0 \\
\hline 7 & 2 & 0.2 & $0.13196 \cdot 10^{-6}$ & $0.13379 \cdot 10^{-6}$ & 34350.0 & 86761.0 \\
\hline 8 & 2 & 0.1 & $0.74079 \cdot 10^{-6}$ & $0.79070 \cdot 10^{-6}$ & 98473.0 & $0.30589 \cdot 10^{6}$ \\
\hline 9 & 2 & 0.05 & $0.28559 \cdot 10^{-5}$ & $0.32842 \cdot 10^{-5}$ & $0.24430 \cdot 10^{5}$ & $0.78972 \cdot 10^{6}$ \\
\hline 10 & 2 & 0.0125 & $0.91102 \cdot 10^{-5}$ & $0.49336 \cdot 10^{-4}$ & $0.95348 \cdot 10^{6}$ & $0.70006 \cdot 10^{7}$ \\
\hline 11 & 3 & 0.335 & $0.33241 \cdot 10^{-7}$ & $0.35843 \cdot 10^{-7}$ & 15554.0 & 37260.0 \\
\hline 12 & 3 & 0.2 & $0.13943 \cdot 10^{-6}$ & $0.16202 \cdot 10^{-6}$ & 36886.0 & $0.10193 \cdot 10^{6}$ \\
\hline 13 & 3 & 0.1 & $0.83122 \cdot 10^{-6}$ & $0.11392 \cdot 10^{-5}$ & $0.11894 \cdot 10^{6}$ & $0.37431 \cdot 10^{6}$ \\
\hline 14 & 3 & 0.05 & $0.37553 \cdot 10^{-5}$ & $0.61361 \cdot 10^{-5}$ & $0.35287 \cdot 10^{6}$ & $0.11612 \cdot 10^{7}$ \\
\hline 15 & 3 & 0.0125 & $0.15372 \cdot 10^{-4}$ & $0.61528 \cdot 10^{-4}$ & $0.21505 \cdot 10^{7}$ & $0.77780 \cdot 10^{7}$ \\
\hline
\end{tabular}

Table 2: Calculations results at three ribs in every direction

\begin{tabular}{|c|c|c|c|c|c|c|}
\hline № & $\begin{array}{c}\text { Plate length, } \\
\mathrm{m}\end{array}$ & $\begin{array}{l}\text { Plate thickness, } \\
\text { m }\end{array}$ & $\begin{array}{l}\text { Deflection in the cen- } \\
\text { tre of plate, } m\end{array}$ & $\begin{array}{l}\text { Maximum deflec- } \\
\text { tion, } \mathrm{m}\end{array}$ & $\begin{array}{c}\text { Stress in the centre of } \\
\text { plate, } \mathrm{Pa}\end{array}$ & Maximum stress, $\mathrm{Pa}$ \\
\hline 1 & 1 & 0.335 & $0.13389 \cdot 10^{-7}$ & $0.13389 \cdot 10^{-7}$ & 7955.4 & 17760.0 \\
\hline 2 & 1 & 0.2 & $0.48691 \cdot 10^{-7}$ & $0.48691 \cdot 10^{-7}$ & 15278.0 & 42616.0 \\
\hline 3 & 1 & 0.1 & $0.20846 \cdot 10^{-6}$ & $0.20846 \cdot 10^{-6}$ & 21479.0 & $0.12681 \cdot 10^{6}$ \\
\hline 4 & 1 & 0.05 & $0.60274 \cdot 10^{-6}$ & $0.60274 \cdot 10^{-6}$ & 3719.5 & $0.24769 \cdot 10^{6}$ \\
\hline 5 & 1 & 0.0125 & $0.15114 \cdot 10^{-5}$ & $0.25811 \cdot 10^{-5}$ & 29252.0 & $0.99685 \cdot 10^{6}$ \\
\hline 6 & 2 & 0.335 & $0.30073 \cdot 10^{-7}$ & $0.30073 \cdot 10^{-7}$ & 14047.0 & 31870.0 \\
\hline 7 & 2 & 0.2 & $0.11820 \cdot 10^{-6}$ & $0.11826 \cdot 10^{-6}$ & 30610.0 & 81011.0 \\
\hline 8 & 2 & 0.1 & $0.57776 \cdot 10^{-6}$ & $0.58133 \cdot 10^{-6}$ & 68838.0 & $0.26482 \cdot 10^{6}$ \\
\hline 9 & 2 & 0.05 & $0.18358 \cdot 10^{-5}$ & $0.18650 \cdot 10^{-5}$ & $0.10883 \cdot 10^{6}$ & $0.56548 \cdot 10^{6}$ \\
\hline 10 & 2 & 0.0125 & $0.50087 \cdot 10^{-5}$ & $0.71327 \cdot 10^{-5}$ & $0.27826 \cdot 10^{6}$ & $0.17775 \cdot 10^{7}$ \\
\hline 11 & 3 & 0.335 & $0.32609 \cdot 10^{-7}$ & $0.33511 \cdot 10^{-7}$ & 15221.0 & 34864.0 \\
\hline 12 & 3 & 0.2 & $0.13393 \cdot 10^{-6}$ & $0.14054 \cdot 10^{-6}$ & 34919.0 & 89049.0 \\
\hline 13 & 3 & 0.1 & $0.73207 \cdot 10^{-6}$ & $0.79656 \cdot 10^{-6}$ & 92505.0 & $0.31336 \cdot 10^{6}$ \\
\hline 14 & 3 & 0.05 & $0.26635 \cdot 10^{-5}$ & $0.29672 \cdot 10^{-5}$ & $0.16928 \cdot 10^{6}$ & $0.74031 \cdot 10^{6}$ \\
\hline 15 & 3 & 0.0125 & $0.80409 \cdot 10^{-5}$ & $0.10902 \cdot 10^{-4}$ & $0.61525 \cdot 10^{6}$ & $0.21138 \cdot 10^{7}$ \\
\hline
\end{tabular}

Table 3: Calculations results at five ribs in every direction

\begin{tabular}{|c|c|c|c|c|c|c|}
\hline № & $\begin{array}{c}\text { Plate length, } \\
\text { m }\end{array}$ & $\begin{array}{l}\text { Plate thickness, } \\
\text { m }\end{array}$ & $\begin{array}{l}\text { Deflection in the cen- } \\
\text { tre of plate, } m\end{array}$ & $\begin{array}{l}\text { Maximum deflec- } \\
\text { tion, } \mathrm{m}\end{array}$ & $\begin{array}{c}\text { Stress in the centre of } \\
\text { plate, } \mathrm{Pa}\end{array}$ & Maximum stress, $\mathrm{Pa}$ \\
\hline 1 & 1 & 0.335 & $0.11778 \cdot 10^{-7}$ & $0.11778 \cdot 10^{-7}$ & 6751.2 & 15524.0 \\
\hline 2 & 1 & 0.2 & $0.40091 \cdot 10^{-7}$ & $0.40091 \cdot 10^{-7}$ & 11747.0 & 34979.0 \\
\hline 3 & 1 & 0.1 & $0.15586 \cdot 10^{-6}$ & $0.15586 \cdot 10^{-6}$ & 12809.0 & 97694.0 \\
\hline 4 & 1 & 0.05 & $0.42661 \cdot 10^{-6}$ & $0.42661 \cdot 10^{-6}$ & 7047.3 & $0.19694 \cdot 10^{6}$ \\
\hline 5 & 1 & 0.0125 & $0.10512 \cdot 10^{-5}$ & $0.12513 \cdot 10^{-5}$ & 26067.0 & $0.51763 \cdot 10^{6}$ \\
\hline 6 & 2 & 0.335 & $0.27603 \cdot 10^{-7}$ & $0.27603 \cdot 10^{-7}$ & 12725.0 & 29379.0 \\
\hline 7 & 2 & 0.2 & $0.10196 \cdot 10^{-6}$ & $0.10196 \cdot 10^{-6}$ & 25555.0 & 70503.0 \\
\hline 8 & 2 & 0.1 & $0.43981 \cdot 10^{-6}$ & $0.44004 \cdot 10^{-6}$ & 45213.0 & $0.20985 \cdot 10^{6}$ \\
\hline 9 & 2 & 0.05 & $0.12610 \cdot 10^{-5}$ & $0.12647 \cdot 10^{-5}$ & 55622.0 & $0.45169 \cdot 10^{6}$ \\
\hline 10 & 2 & 0.0125 & $0.33254 \cdot 10^{-5}$ & $0.36705 \cdot 10^{-5}$ & $0.16658 \cdot 10^{6}$ & $0.76841 \cdot 10^{6}$ \\
\hline 11 & 3 & 0.335 & $0.30857 \cdot 10^{-7}$ & $0.31129 \cdot 10^{-7}$ & 14298.0 & 32159.0 \\
\hline 12 & 3 & 0.2 & $0.12079 \cdot 10^{-6}$ & $0.12261 \cdot 10^{-6}$ & 30766.0 & 80491.0 \\
\hline 13 & 3 & 0.1 & $0.58325 \cdot 10^{-6}$ & $0.59784 \cdot 10^{-6}$ & 64778.0 & $0.26189 \cdot 10^{6}$ \\
\hline 14 & 3 & 0.05 & $0.18283 \cdot 10^{-5}$ & $0.18861 \cdot 10^{-5}$ & 86161.0 & $0.59881 \cdot 10^{6}$ \\
\hline 15 & 3 & 0.0125 & $0.51203 \cdot 10^{-5}$ & $0.55609 \cdot 10^{-5}$ & $0.30511 \cdot 10^{6}$ & $0.92375 \cdot 10^{6}$ \\
\hline
\end{tabular}




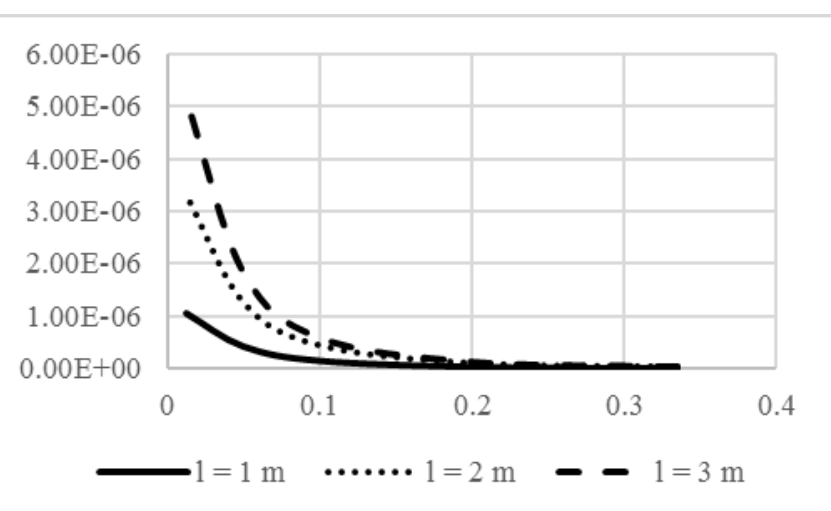

Fig. 3. Graphics of relation between deflection in the centre of the plate (vertical axis, $\mathrm{m}$ ) to its thickness (horizontal axis, $\mathrm{m}$ ) at five ribs

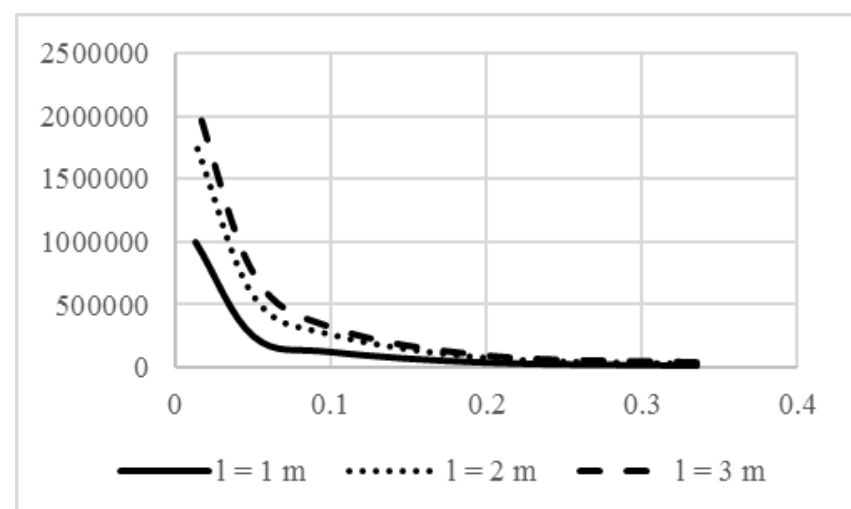

Fig. 4. Graphics of relation between maximum stresses in the plate (vertical axis, Pa) to its thickness (horizontal axis, m) at three ribs

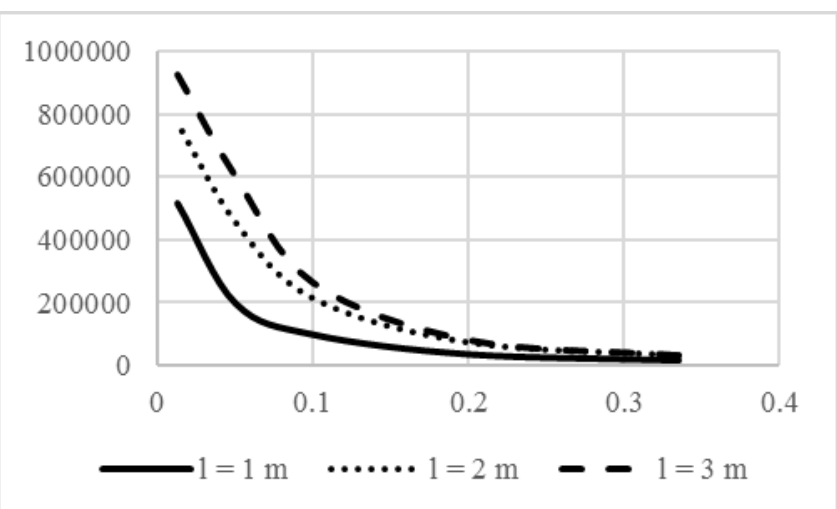

Fig. 5. Graphics of relation between maximum stresses in the plate (vertical axis, Pa) to its thickness (horizontal axis, m) at five ribs

\section{Conclusion}

The discrepancy in the results obtained by the author's method and the finite element method increases with the ratio of the height of the transverse reinforcing beam to the thickness of the plate, and is practically independent of the ratio of the height of the longitudinal reinforcing beam to the thickness of the plate. In performed studies this ratio was $0.125,0.5$ and 1.0. Maximum error of calculations was $1 \%, 1.8 \%, 2.4 \%$ respectively, that is acceptable for practical calculations. Tendency of an increase in the error is obvious. To determine the limits of applicability of a new approach to the calculation of plate-beam systems proposed by the authors on the basis of the numerical and analytical method of boundary elements (based on the usual 5\% in design practice), it is necessary to continue research with other parameter ratios.

\section{References}

[1] A.F. Daschenko, L.V. Kolomiets, V.F. Orobey, N.G. Surianinov, Chislenno-analiticheskiy metod granichnykh elementov, VMV, Odessa, (2010), 512 p. (in Russian)

[2] N.G. Surianinov, "Osnovnie polozheniya chislennoanaliticheskogo metoda granichnykh elementov", Stroitelnaya mehanika I raschet sooruzheniy, No.6 (251), (2013), pp.52-58

[3] V.F. Orobey, N.G. Surianinov, "Substantive provisions of Numeral-analytical boundary element method", Magazine of Civil Engineering, No.4 (22), (2011), pp.33-39, available online: http://engstroy.spbstu.ru/index_2011_04/suryaninov_MGE.pdf, last visit: 11.02.2018, (in Russian)

[4] S.L. Crouch, A.M. Starfield, Boundary Element Methods in Solid Mechanics: With Applications in Rock Mechanics and Geological Engineering, George Allen \& Unwin, (1983), 322 p.

[5] Brebbia C.A., Recent Advances in Boundary Element Methods, Pentech Press, London, (1978), 464 p.

[6] Benerji P., Batterfield R., Metody granichnykh elementov v prikladnykh naukah, Mir, Moscow, (1984), 494 p. (in Russian)

[7] Diakonov V.P., MATLAB 6/6.1/6.5 + Simulink 4/5 v matematike I modelirovanii. Osnovy primeneniya. Polnoe rukovodstvo polzovatelya, SOLON-Press, Moscow, (2003), 576 p. (in Russian)

[8] Campbell S., Modeling and Simulation in Scilab/Scicos, Springer, New York, (2006), 313 p.

[9] H. Pasheku, Programirovanie v Borland Delphi 2006 dlya professionalov. Delphi for .NET Developer's Guide, Williams, Moscow, (2006), $944 \mathrm{p}$.

[10] Yu.V. Korniyenko, M.G. Surianinov, "Development of CAD implementing the algorithm of boundary elements' numerical analytical method", Pratsi Odeskogo politehnichnogo universitetu, No.1 (45), (2015), pp: 128-133, available online: http://pratsi.opu.ua/app/webroot/articles/1428656669.pdf, last visit: 11.02.2018, (in Russian) 